\title{
Care Provider Order Entry (CPOE): A Perspective on Factors Leading to Success or to Failure
}

\author{
A. Ozdas, R. A. Miller \\ Department of Biomedical Informatics, Vanderbilt University Medical Center, Nashville, TN, USA
}

\begin{abstract}
Summary
Objective: Authors provide a perspective on factors leading to successful care provider order entry ( $\mathrm{POE}$ ) implementations.

Methods: Viewpoint of authors supported by background literature review.

Results: Authors review both benefits and challenges related to CPOE implementation using three guiding principles: (1) a clinical approach to clinical systems, which claims that CPOE implementation is analogous to a "good" clinician delivering care to a patient; (2) a commitment to quality, which advocates that no compromises should be made in implementing system functionality and clinical system content - the highest objective for CPOE implementation is to provide better quality of care and increased safety for patients; (3) a commitment to fairness, as evidenced by respect for individuals and support of local autonomy, which advocates for minimizing disruptions to clinician-users' workflows, and adequate local control over CPOE system design and evolution, including clinical content management.

Conclusions: Past experiences with CPOE implementation can inform future installation attempts. Sociocultural factors dominate in determining the success of implementation, and should govern technical factors.
\end{abstract}

\section{Keywords}

Medical order entry systems; socioeconomic factors; decision making, organizational; decision support systems, linical; practice guidelines; hospital information systems; physician's practice patterns

Geissbuhler A, Haux R, KulikowskiC, editors. IMIA Yearbook of Medical Informatics 2007. Methods Inf Med 2007; 46Suppl 1 : 128-37

\section{Introduction}

The authors believe that three principles determine if care provider order entry (CPOE) system projects will succeed: a clinical approach to clinical systems; a commitment to quality; and, a commitment to fairness, as evidenced by respect for individuals and support of local autonomy. The principles pertain to individual users and to institutions deploying CPOE systems. Attention to these principles can guide future successful installations.

The literature documents substantial benefits of CPOE systems. For example, in the 1990s the Institute of Medicine (IOM) of the U.S. National Academy of Sciences reviewed inadequacies of clinical care delivery, and recommended widespread implementation of CPOE to improve safety and quality of healthcare delivery [1][2]. Similar evidence prompted the Leapfrog group, a coalition of America's largest corporations, to designate CPOE implementation as one of its three patient safety goals [3]. Studies demonstrate that CPOE systems can improve order processing (e.g., turnaround times, and awareness of results) [4-6]. By contrast, a growing literature also documents adverse consequences of CPOE implementation. Ash and colleagues reported that only $9.6 \%$ of U.S. hospitals have a CPOE system in place [7], that $\mathrm{CPOE}$ installation can generate nine categories of unintended adverse consequences [8], and that emotional, as well as financial damage may follow installation $[9,10]$. Furthermore, in 2005, half of vendors' electronic outpatient prescribing systems lacked functional capabilities essential for quality of care and cost reduction [11]. The authors provide herein a balanced view of benefits and shortcomings of CPOE.

\section{What Is CPOE?}

Care provider order entry (CPOE) allows licensed healthcare providers physicians, nurses, and others treating patients - to enter, via a computer system, orders relevant to the patient's tests or therapies [12]. In typical CPOE interactions users first "authenticate" by name and password. Next, they select a patient, create new orders or modify existing ones, review the order session, and "final accept" orders to have them carried out [13]. During this process, the CPOE system may provide decision support - advice on how to: (a) create more legible, correct, and actionable orders; (b) create patient-appropriate clinical orders; (c) optimize clinical processes (improve workflow, and be cost-effective and regulatory-compliant); and, (d) provide just-in-time, focused education relevant to patient care [13]. After "final accepting," orders go to ancillary departments (e.g. lab, pharmacy, radiology) for immediate action [13]. 


\section{A Brief History of CPOE}

Possibly the first successful (long-lasting and used by most physicians on staff) CPOE system implementation in the USA took place in the early 1970s at El Camino Hospital in California [14]. Designed by Technicon Data Systems (TDS), one of the first commercial developers of CPOE systems, the system followed upon earlier work by Lockheed Corporation [15]. The implementation demonstrated CPOE's potential for improving patient care through creating complete medication orders and by capturing the indications radiology and electrocardiography procedures [14].

In the U.S., much of the early knowledge about CPOE systems, including studies demonstrating CPOE's potential to improve quality of care, originated from three academic medical centers: (1) the Regenstrief Institute of the University of Indiana (The Regenstrief Medical Record System, or RMRS, and the Medical Gopher) [16], (2) Brigham and Women's Hospital, associated with Harvard University (Brigham Integrated Computer System, or BICS) [17] and (3) the University of Utah (Health Evaluation through Logical Processing, or HELP) [18]. More recently, the U.S. Veterans Administration has pioneered exemplary systemwide CPOE [19]. The RMRS CPOE implementation at Wishard Memorial Hospital in Indianapolis began in the mid-1980s, following earlier outpatient development. The RMRS pioneered use of patient-specific reminders to increase guideline adherence $[20,21]$. At LDS Hospital, the HELP System was one of the earliest to employ patient data-driven decision support - e.g., recently combining the admission diagnosis, white-cell count, temperature, surgical data, chest radiograph, and information from pathology, serology, and microbiology labs to recommended appropriate antimicrobial therapy [22]. The BICS, developed in the early 1990s, illustrated CPOE's potential to reduce adverse drug events (ADE) and serious medication errors [23, 24].

Similar experiences with CPOE development occurred world-wide. After 1970, hospital information systems (HIS) with integrated order management components evolved in many European countries. For example, DIOGENE, the pioneering HIS developed by Scherrer et al. at the University of Geneva Hospital, provided patient-specific knowledge to physicians to make more appropriate decisions [25-27]. Early HIS efforts by Peterson and colleagues for the Stockholm County Health Care evolved to later installation of a commercial system [28]. More recently, Stockholm County Council developed and implemented an outpatient CPOE system in its metropolitan area [29]. In the Netherlands, early HIS development at Leiden University Hospital included an integrated CPOE component. Its successful operational system was later commercialized [30], and installed in an academic medical center - improving prescription quality - more complete medication orders, and correct doses [31]. After 1980, a Dutch research team at Erasmus University developed "ELIAS", another pioneering information system with embedded decision support for the primary care setting $[32,33]$. It improved general practitioners' ordering behavior in many areas, including test ordering [34, 35] and treatment of asthma and hypertension [36].

In Japan, CPOE development efforts occurred after 1984 [37, 38]. Ogura et al. demonstrated that $\mathrm{CPOE}$ reduced prescription errors and decreased inquiries by pharmacists [39]. Japanese use of CPOE systems has steadily expanded [40]; a 1999 survey indicated
$20 \%$ of Japanese hospitals had CPOE systems [41]. At Osaka University Hospital, CPOE was reported to reduce laboratory and pharmacy turnaround times and reduce redundant treatment orders [42]. A Republic of Korea survey revealed that the majority $(80 \%)$ of hospitals had CPOE systems but only 9\% integrated CPOE with complete EMR systems [43]. A study by Hwang et al., in a Korean academic hospital, showed that CPOE decreased the number of urgent "stat" diagnostic tests, improved ability to audit medical services that patients received, and decreased length of stay [44]. Park et. al. later studied 212 Korean general hospitals and showed that CPOE significantly increased revenues for both inpatient and outpatient practices [45]. Similar reports of successful CPOE implementations occurred in Canada [46] and Australia [5].

\section{Benefits of CPOE}

In a 2003 review, Kuperman and Gibson [47] noted that prior controlled studies from at least one institution documented each of the following CPOE benefits: increased adoption of preventive care measures for inpatients (pneumococal vaccine and influenza vaccine [20], prophylactic aspirin [20, 48], prophylactic subcutaneous heparin $[20,49]$ with significantly reduced rates of DVT and pulmonary embolism [50]); increased compliance with formulary and dosing guidelines for inpatient prescriptions [23, 24, 49, 51]; increased compliance with drug monitoring recommendations [52]; decreased laboratory test ordering for outpatients after clinicians shown either cost of test about to be ordered, or recent previous results of test to be ordered, or likelihood estimate that test to be ordered would be abnormal [53] [54, 55] [56, 
57] [58]; decreased ordering of redundant laboratory tests for inpatients [56, 57]; increased compliance with recommended radiology imaging procedures for inpatients [59-61]; decreased rate of potential adverse drug events and of serious medication errors in inpatients [62-64]; and, a potential reduction in both total hospital costs [22, 65] [66] [67] and inpatient length of stay.

CPOE-based medication dose adjustments benefit the elderly population [68]. Similar improvements accrue for pediatric dosing based on the patient's age, weight, and (for neonates) gestational age $[6,69]$. Researchers can analyze CPOE-related data repositories to determine treatment outcomes for various populations, and review appropriateness of the therapies provided [70]. Diagnosis and procedure specific CPOE order sets (collections, often "evidence-based" or "best-practicesummaries", of recallable individual orders pre-specified as relevant to a given condition [71, 72]) can decrease variation in care and increase compliance with guidelines [48, 73]. Ozdas et al. demonstrated that an "admission advisor" could increase utilization of an evidence-based order set and reduce errors of omission [48]. Implementation of disease-specific CPOE tools can streamline discharge processes and improve compliance with quality measures [74].

\section{Applying The Three Guiding Principles}

Published recommendations for successful CPOE implementations [75] and for establishment of effective decision support [76-78] can benefit healthcare organizations planning to develop or install CPOE systems.

\section{Clinical Approach to Clinical Systems}

A single perspective, critical to understand when implementing complex computer-based healthcare systems, is that clinical systems must be viewed clinically, i.e., from the viewpoint of expert practitioners who treat patients. One of the early U.S. pioneers of CPOE, Dr. Clement J. McDonald, noted in a 2004 editorial that "computers could be [viewed as] the 'chicken soup' for many illnesses of the healthcare system". In the current authors' opinion, a CPOE system does not merely represent an installation to improve infrastructure that is purchased by administrators and implemented by the institution's information technology team and vendors. Complex informatics systems radically change healthcare providers' workflows, and dramatically alter how clinical care might be, and will be, delivered. Therein lies both the tremendous potential of such systems to accomplish good, and the corresponding potential to wreak havoc.

To extend McDonald's analogy [79], the authors believe that an institution installing CPOE should view the practicing healthcare providers who comprise the "user group" and the institution itself, because it provides healthcare - as the "patient". The CPOE system represents a new treatment for specifically identified illnesses of the institution. All involved should view CPOE implementation as following an approach similar to how an ideal ("good") clinician would deliver care to a patient.

The institution's system development and implementation team must serve in the role of the "good clinician" when a CPOE system is selected and installed by the organization. A good (ideal) clinician, in treating a patient, does not dispense arbitrary therapies and does not ignore the patient's response to thera- pies. The authors describe below ideal behavior for a "good" clinician in ital$i c s$, and draw comparisons with ideal (and unsuccessful) informatics implementations.

First, the good clinician must listen to the patient and examine the patient to determine what problems amenable to therapy exist. The clinician carries out tests to confirm hypotheses before dispensing potentially dangerous treatments. The good clinician identifies treatment objectives (desired outcomes) and determines how best to measure progress toward those objectives.

The implementation team, consisting of clinical and informatics personnel, supported by administrators and by workflow experts, must determine what illnesses afflict the organization (problems in healthcare delivery) that a the CPOE system might address. No implementation should occur in the absence of identified problems. The implementation team, supported by clinicians, administrators, and IT staff, must determine what objective metrics will measure institutional progress in addressing the problems. In a 2003 report of factors contributing to successful CPOE installations [75], Ash and colleagues noted that a key factor was motivation for CPOE implementation, whereby clinical practitioners, technology staff, and institutional administration must have a shared vision of the problems to be solved and how to approach them using CPOE.

The good clinician carefully takes into consideration the effect of the disease, and of the therapy, on the patient's wellbeing and on the patient's family and environment.

Aarts and colleagues [80], in reporting factors leading to a failed attempt to install a CPOE system in a Dutch academic hospital, emphasized that CPOE rollout involves an exercise in "mutual shaping" whereby the system must be 
tailored to its intended environment, to match clinicians' workflows, and the clinicians must alter their work patterns to take better advantage of what the system has to offer. For example, a large existing technical staff and computing infrastructure that had previously supported accounting and inventory systems might experience difficulty in supporting new paradigms associated with clinical computing applications [80]. Similarly, few benefits accrue when a CPOE system conveys medication orders to the pharmacy system by producing paper printouts that pharmacists must then enter manually into the pharmacy computer [80]. Aarts et al identified project and system ownership as a key success factor; if clinicians, administrators, and information technologists do not collectively view all problems associated with system deployment and usage as "their own" problems, divisive "finger pointing" can occur [80].

Coiera expressed similar sentiments in a 2004 article titled "Four rules for the reinvention of healthcare" [81]. His four rules stated that technical systems have social consequences, social systems have technical consequences, that developers should design sociotechnical systems and not simply technology, and that to do the latter, institutions must understand how clinician-users and technology interact [81]. Georgiou and Westbrook, in a 2006 review article, listed ten important questions to ask regarding new CPOE system implementation [82]. Among their ten questions were: what does the organization expect to gain by introducing the system, and how will the benefits be measured; who wants or needs the proposed functionality, and why; which groups should be most involved in making decisions about mechanics of implementation; what changes to work practices and processes are required; and, can the sys- tem be tailored to fit the specific needs of healthcare professionals [82].

In the authors' experience, the clinical staff must determine the nature and dosage of the selected therapy (clinical system implementation details). Just as clinical practitioners start with a low dose of a medication and work their way up to a higher dose if patients need and tolerate such increases, implementation of potentially disruptive systems must be done gradually. Initially, a few volunteer testers using fictitious patients provide feedback to developers. Developers must address concerns before proceeding. Then additional volunteers iteratively use fictitious patients to provide additional feedback about system function and anticipated effects on work flows. Beuscart-Zephir and colleagues [83] analyzed the impact of CPOE medication ordering-related functions on doctor-nurse communications and cooperation. Confirming similar findings by Coiera [84], the French investigators found that going from paper-based ordering to CPOE can potentially disrupt established patterns of synchronous cooperation and interfere with customary methods for distributed decision-making. Campbell and colleagues characterized such technology-related disruptions as "illusions of communication" [8].

Aarts et al [80] described the importance of training of end-users in determining the success of CPOE implementation. In the current authors' experience, clinical leaders must plan for training, and once system design has advanced to stability, and the CPOE system is approximately in the form anticipated for "go-live", the institution must train all affected end-users 1-4 weeks before the actual "go live" date. Training schedules must take into account that the users already have fulltime jobs, and absenteeism (due to vacations and other causes) cannot be allowed to compromise adequate preparedness. The installation team should include the institution's best employees - staff who are highly regarded by their peers - who are recruited from their previous jobs to create a full-time "support services" team for training and go-live. These individuals, who are already experienced problem-solvers familiar with institutional policies, procedures, and personnel, become expert trainers for the soon-to-be implemented software system. End-users value training offered by trusted colleagues over that of strangers brought in from outside. After training the future end-users, during the initial go-live and for 1-3 weeks thereafter, the support services team works on-site on the "golive" unit(s) to ensure successful system initiation.

The good clinician regularly monitors the patient's progress over time, in an appropriately frequent manner, to ascertain progress toward desired objectives.

The good clinician is also mindful that treatments can have adverse side effects, and must work with the patient to monitor for such side effects. The good clinician is also aware that the course of a patient's illness will vary over time, both due to the natural history of the underlying disease process, and due to the patient's response to therapies. If the patient returns with adverse effects or progression of underlying disease, the good clinician determines if they are severe enough to warrant change, or even cessation, of the therapy.

Among Bates et al's ten commandments for effective clinical decision support was the admonition to "monitor impact, get feedback, and respond" [76]. In listing unintended consequences of CPOE installation, Campbell et al. included the following: more and new work for clinicians; issues of changed workflow patterns; never-ending demands for 
changes in hardware and software capabilities; negative emotional reactions by clinician-users; over-dependence on technology to the point that people cannot function well in its absence (e.g., during "downtime" events); and, new kinds of errors introduced by CPOE [8]. In the authors' opinion, it is possible to design and construct prospectively approximately $80-90 \%$ of the correct and appropriate functionality of a $\mathrm{CPOE}$ system. This requires months of intensive, interactive design sessions involving clinically savvy system developers and large numbers of representative future system end-users. Yet, communication between developers and users, no matter how well-intentioned or thorough, is inherently flawed. In isolation, away from their actual work environments, clinical staff will describe idealized job activities, and not mention the disruptive chaos that constantly distracts them during work hours. As McDonald observed, "healthcare workers use computers in short bursts and flit among computers like honeybees among flowers" [79]. Conversely, system developers attempting to describe the system to future end-users relate idealized system functionalities that later become rigidly implemented (due to the nature of software code), and which cannot flexibly support unexpected, chaotic workflows. Even exemplary human-computer usability laboratories cannot fully mimic the truly disruptive nature of care delivery, due to the labor-intensive cost of creating and carrying out such simulations, and due to the improbability of many situations that actually occur. Nevertheless, formal or informal human-usability testing is an important component of CPOE development.

In the authors' opinion, the result of the flawed communication between developers and future end-users is that the time immediately following the $\mathrm{CPOE}$ system "go live" date provides a critical learning experience. Unfortunately, many commercial system vendors view the most important components of system installation as the sales process through the "go live" date, after which vendors substantially diminish on-site and general support. The authors believe that at go-live, careful and close observation of the effect of the system on end-users, coupled with intensive on-site support by the previously-described support team - can make the critical difference between a successful installation and one that encounters increasing clinician resistance and ends in failure. System developers must be "on call" to address problems identified during this time through rapid CPOE software modifications. Early identification of problems that comprise the $10-20 \%$ gap between system design at time of "go-live" and what is required to address actual workflows and other problems discovered following go-live is of utmost importance. A dedicated oversight team must review ongoing progress once or preferably twice daily, to identify problems during go-live, assign solution of the problems to the most capable and appropriate personnel, determine the shortest realistic timeline to have the solution "in production", communicate the proposed solution and timeline to clinicianend users for commentary and feedback, and then monitor successful placement of the solution into production for the CPOE system. The oversight should consist of: clinician informaticians involved in CPOE design who can rapidly understand and design additional system software changes; IT staff leadership; clinical site leadership (e.g., unit nurse managers and clinician champions); the team of system support personnel who are on the ward 24 hours per day, 7 days a week, until success is at hand; representatives of installation site's practicing clinicians (doctors, nurses, pharmacists, ward secretaries, ancillary service members) who have experienced problems during the "golive" event; and, representative leaders of institutional administration (some solutions involve policy changes for the clinical institution that must be rapidly initiated). Aarts et al commented on the slow-downs in clinical work that can occur post CPOE system go-live, and recommended adding extra staff to accommodate such problems [80]. They also noted that it is not adequate for the clinical leadership of a large hospital CPOE installation to come from a staff physician who only devotes halftime effort (or less) to the CPOE project, while still maintaining a clinical practice [80].

During early CPOE implementation at the authors' institution, the surgical staff complained that they were losing significant patient care time and potential revenue because the operating room schedule was delayed when surgeons diligently entered all CPOE orders before arriving in the operating room (OR) in the morning. The CPOE oversight team invoked a local heuristic rule that "a clinician should never let use of the CPOE system interfere with good patient care". A joint decision by hospital administration, IT staff, and clinical installation site staff was that the surgeons, when pressed for time to go to the OR during morning rounds, could write non-urgent routine orders on paper, and that the ward secretaries would enter corresponding $\mathrm{CPOE}$ orders for the surgeons. One exception was that surgeons were encouraged to use the CPOE system to enter medication orders, due to the inherent safetychecking provided by the CPOE system. After this change in policy, surgerons' workflow patterns improved. The surgeons were much more accepting of the CPOE system, and the OR 
schedule was no longer delayed. Rapid identification and addressing of such critical problems in the earliest days of CPOE "go-live" is critically important. Finally, the good clinician is aware that knowledge of medicine and of best practices is in a state of constant evolution, so that what is "best therapy" today may not be so tomorrow.

Routine weekly interactions between the clinical informatics CPOE development staff and representative endusers must continue indefinitely. At the authors' institution, this is accomplished through noontime conferences during which the Informatics Center provides free-of-charge pizza luncheons for care providers who regularly use the system in exchange for their candid comments about system function, their input on how best to accomplish planned changes to the system, and solicitation of their ideas for new, useful CPOE system features that might improve the quality of care at the institution, and how to ameliorate the clinicians' workloads.

\section{Commitment to Quality}

A critical factor in CPOE implementation and maintenance is that the institution and its personnel must commit to do what is right, not just what is expedient. Aarts et al noted that the changes associated with CPOE implementation are unpredictable [80], and Ash et al identified the financial and resource-related ability to overcome obstacles as a critical success factor in implementation [75].

McDonald et al. characterized CPOE installation as a "journey, not a destination" [79]. Nevertheless, too many institutions treat buying and installing a CPOE system in the manner that one purchases a new car - adding all optional features "up front" at time of purchase and attempting to limit expenditures beyond the initial purchase price. The authors' favored analogy for CPOE installation is the purchase of a modularly designed personal computer - whereby one plans over time to replace the video card and monitor as technology advances, and to add more memory or disk storage capacity as it becomes available through technological advances. The old British idiom, "penny wise and pound foolish" makes it unwise to invest a million or more pounds/euros/dollars in purchasing a CPOE system, but to allow installation to fail for lack of additional resources. A key informatics principle is that attainment of quality requires tight feedback in various forms. System developers and maintainers must seek out ongoing comments from end users (formative evaluation) and launch periodic formal evaluations to insure that the system performs the tasks expected of it (summative evaluation).

Dr. William Stead, a visionary leader in institution-wide informatics systems, has long emphasized several important quality-related principles [85]. First, an institution must have an overall informatics architectural plan, and must adhere to it. Second, the perfect cannot be the enemy of the good. If implementing a much-needed project or application cannot follow the existing architectural plan in a reasonable amount of time, it is permissible to proceed in implementing the functionality in a compromised ("one-off") manner if and only if there is a known way to replace the "temporary patch" in a manner consistent with the overall architecture, and there is a plan in place to do so over time. Third, it is important that the right person (the one most likely to know the correct information, and the one most likely to use an application) enter information into a clinical application only once, and that the information be replicated so that others need not enter it (e.g., incorrectly).
Fourth, implementations should not occur unless there are known methods to scale the application to the institutional (or larger) level, and known methods to sustain the needs of the application (in terms of software, hardware, and clinical content support). Side effects of not following Stead's guidelines can be serious. For example, Koppel et al. discovered that majority of the errors in a difficult CPOE installation at his institution were due to lack of integration of CPOE into the hospital's clinical information systems and $\mathrm{CPOE}$ design not corresponding to clinical workflow [86].

In the authors' opinion, it is important to have a number of quality and safety related guidelines in place during CPOE selection, installation, and evolution. The first, taken from the Hippocratic Oath, is primum non nocere "first, do no harm." This means that system clinical content must be accurate and up to date, and requires local oversight because vendors and governmental regulators are not always capable of insuring the quality required locally [78, 87].

Institutions deploying CPOE must use a systematic, database-based approach to tracking clinical content. A named member of the clinical staff must responsible for each specific item of content (e.g., an order set or a specific automated guideline protocol). The database must track when each component was last updated and by whom, when it is anticipated that it will require review and further update, and prior evidence-based resources used in constructing the content. With such a system, an institution can prospectively maintain updates. Recommendation 10 on Bates et al's "Ten Commandments for Effective Clinical Decision Support" was to "Manage and Maintain Your Knowledge-based Systems" [76]. Without feedback from real-world us- 
ers attempting to use informatics systems during care delivery, no evolution of the artifacts toward greater utility can occur. An example of this phenomenon is the pharmacy/drug information knowledge bases underlying commercial CPOE systems. Drug-allergy and drug-drug interaction alerts generated by commercial CPOE knowledge bases are excessive, clinically irrelevant and a major disruptor of clinicians' workflows [78, 88]. Keeping such clinical information content up to date locally is critical, or an institution may be put at risk, in terms of quality of care delivered, by perfectly adhering to CPOE guidelines that represent "best medical practices" of five to ten years ago.

Given that more and more healthcare organizations are implementing commercial CPOE systems, initiatives to evaluate them are essential both with respect to safety. Current evaluation approaches have targeted primarily "academic one-of-a-kind" products and not what is actually installed at most sites nationally. It is crucial that organizations perform ongoing evaluation of their CPOE applications to monitor their effectiveness [89]. Similarly, vendors must evaluate the quality of the clinical content of the systems that they provide, and insure that the content is relevant and current.

\section{Commitment to Fairness, Including Respect for Individuals and Support of Local Autonomy}

System implementers, whether individuals, institutional leadership groups, or vendors, should follow the golden rule as a key part of CPOE implementation: do unto others as you would have them do unto you [75]. All involved in the CPOE project must respect end-users in same way that a skilled and capable clinician respects his or her patients. This holds true for the manner in which vendors should respect their installation sites (and individuals within them). The best interests of the patient should always be foremost.

McDonald's recommendations for successful CPOE and decision support installation included several fairness and respect-related principles [79]: "too many nonspecific and repetitive reminders are the moral equivalent of email 'spam' and cause the same justified annoyance to the recipient"; physicians should have "escape mechanisms" while using CPOE systems, such as the ability to type "miscellaneous" orders freehand when it is difficult to find a CPOE order that exactly conveys the ordering physician's intentions; institutions should not attempt to extract information from clinician-users during CPOE unless the information is absolutely required to build a complete and accurate order; and, institutions and vendors should work to simplify CPOE so that the time disadvantage of system use is minimized for clinician-users. Miller and colleagues outlined alternative approaches to implement decision support within CPOE systems to minimize intrusiveness, optimize timing of workflow interruptions, and convey alerts in the most appropriate manner [13]. Ash and colleagues, in defining success factors for CPOE installation, included: "how the organization learns from its mistakes"; timely responses to identified problems; adequate user training; "live help at the user's elbow" during go-lives; and, revisiting past decisions on a regular basis [75].

An equally important principle to consider during complex system implementations is autonomy. The ability to control one's destiny, both at the individual provider and at the institutional level, is extremely important in healthcare delivery. A patient will rightfully become disenchanted with his or her physician if the patient perceives that the physician does not listen to them, or listens but does not address the patient's complaints. Similarly, it is critical for the users at a CPOE installation site to believe that they are viewed as important and as having a continued voice in determining system functionality and system evolution. The manner in which computer systems are implemented can either increase or decrease local autonomy, and in doing so, either accomplish good or wreak havoc.

At the vendor-client level, similar concerns for local autonomy are equally important. As previously noted, a major failing of many commercial CPOE vendors is that they do not provide enough local control over system functionality to each site installing their systems. The result is that local sites must register their complaints into long vendor-prioritized queues of requests that also contain requests from other installed sites, with the result that an individual site's requests may be ignored, or scheduled to occur with a remote future vendor upgrade release. While in some ways such vendor behavior is understandable, because the difficulty of supporting hundreds of idiosyncratic CPOE system code configurations is far more difficult than supporting a single vendor-wide code configuration, such a model is not acceptable for clinical care delivery. It is analogous to thinking that it is morally acceptable to provide suboptimal or no care only because a patient cannot afford to pay. The industry requires a new model for CPOE development and installed system support that will provide local sites with enough flexibility to alter their system configuration to adapt to local workflows and requirements, while still allowing the vendor to provide competent centralized support when problems cannot be solved at the local site.

An important related issue is local con- 
trol over implementation of CPOE system clinical content, discussed in part above under "Quality and Fairness". Nebeker et al. demonstrated that CPOE does not help reducing ADEs if it lacks necessary decision support components such as drug selection, dosing and monitoring with continued high rates of ADEs after the implementation of CPOE [90]. Likewise, Bobb et al. estimated that $20 \%$ of the dosing errors would likely be prevented with CPOE, another $50 \%$ was rated preventable only if intelligent decision support that incorporates necessary patient specific data at the time of order entry [64]. In a discussion of CPOE order sets, Bobb et al. [72] noted that there are many difficulties associated with developing and maintaining order sets, which must be done at the local level to be most relevant and effective for clinicians.

\section{Conclusions}

Patient safety and quality of care has become the top priority of many health care organizations. Thoughtfully installed and maintained CPOE systems can improve quality of care by creating complete and legible orders, providing just in time decision support for patient specific treatment options, standardizing care for cost-effective and regulatory compliant care, and providing just-in-time, focused education relevant to patient care. However, when not installed and maintained properly CPOE can potentially facilitate, rather than avert, errors. Healthcare organizations undertaking CPOE system installation should have a balanced perspective, and recognize the $\mathrm{CPOE}$ implementation factors leading to success. A CPOE system must evolve to keep pace with the ever-changing practice of medicine, and represents an ex- cellent mechanism to help individual care providers and institution to do so as well.

\section{Acknowledgments}

The authors would like to thank Antoine Geissbuhler, William Stead, Doug Talbert, Russ Waitman, and many others for their substantial contributions to Vanderbilt's CPOE system. Dr. Miller's work has been supported in part by a grant from the U.S. National Library of Medicine, R01-LM-007995.

\section{References}

1. Kohn LT, Corrigan JM, Donaldson MS. To Err is Human: Building a Safer Health System, Washington D.C.: National Academy Press; 2000.

2. Crossing the Quality Chasm: A New Health System for the 21st Century. Washington D.C.: National Academy Press; 2001

3. The Leapfrog Group for Patient Safety: Rewarding Higher Standards, www.leapfroggroup.org (accessed 04-14-2007)

4. Mekhjian HS, Kumar RR, Kuehn L, Bentley TD, Teater P, Thomas A, et al. Immediate benefits realized following implementation of physician order entry at an academic medical center. J Am Med Inform Assoc 2002;9(5):529-39.

5. Westbrook JI, Georgiou A, Dimos A, Germanos T. Computerised pathology test order entry reduces laboratory turnaround times and influences tests ordered by hospital clinicians: a controlled before and after study. J Clin Pathol 2006;59(5): 533-6.

6. Cordero L, Kuehn L, Kumar RR, Mekhjian HS. Impact of computerized physician order entry on clinical practice in a newborn intensive care unit. $\mathrm{J}$ Perinatol 2004;24(2):88-93.

7. Ash JS, Gorman PN, Seshadri V, Hersh WR. Computerized physician order entry in U.S. hospitals: results of a 2002 survey. J Am Med Inform Assoc 2004;11(2):95-9.

8. Campbell EM, Sittig DF, Ash JS, Guappone KP, Dykstra RH. Types of unintended consequences related to computerized provider order entry. J Am Med Inform Assoc 2006;13(5):547-56.

9. Massaro TA. Introducing physician order entry at a major academic medical center: II. Impact on medical education. Acad Med 1993;68(1):25-30.

10. Massaro TA. Introducing physician order entry at a major academic medical center: I. Impact on organizational culture and behavior. Acad Med 1993;68(1):20-5.

11. Wang CJ, Marken RS, Meili RC, Straus JB, Landman AB, Bell DS. Functional characteristics of commercial ambulatory electronic prescribing systems: a field study. J Am Med Inform Assoc 2005;12(3):346-56.

12. American Hospital Association. AHA Guide to Computerized Order Entry Applications, Washington D.C.: American Hospital Association; 2000.

13. Miller RA, Waitman LR, Chen S, Rosenbloom ST. The anatomy of decision support during inpa- tient care provider order entry (CPOE): Empirical observations from a decade of CPOE experience at Vanderbilt. J Biomed Inform 2005; 38(6):469-85.

14. Sittig DF, Stead WW. Computer-based physician order entry: the state of the art. J Am Med Inform Assoc 1994;1(2):108-23.

15. Bates DW. Computerized physician order entry and medication errors: Finding a balance. J Biomed Inform 2005;38(4):259-61

16. McDonald CJ, Overhage JM, Tierney WM, Dexter PR, Martin DK, Suico JG, et al. The Regenstrief Medical Record System: a quarter century experience. Int J Med Inform1999;54(3):225-53.

17. Teich JM, Glaser JP, Beckley RF, Aranow M, Bates DW, Kuperman GJ, et al. The Brigham integrated computing system (BICS): advanced clinical systems in an academic hospital environment. Int $\mathrm{J}$ Med Inform1999;54(3):197-208.

18. Gardner RM, Pryor TA, Warner HR. The HELP hospital information system: update 1998. Int J Med Inform 1999;54(3):169-82.

19. Brown SH, Lincoln MJ, Groen PJ, Kolodner RM. VistA-U.S. Department of Veterans Affairs nationalscale HIS. Int J Med Inform 2003;69(2-3):135-56.

20. Dexter PR, Perkins S, Overhage JM, Maharry K, Kohler RB, McDonald CJ. A computerized reminder system to increase the use of preventive care for hospitalized patients. NEngl J Med 2001;345(13): 965-70.

21. Overhage, JM,Tierney WM, Zhou XH, McDonald CJ.A randomized trial of "corollary orders" to prevent errors of omission. J Am Med Inform Assoc 1997;4(5):364-75.

22. Evans RS, Pestotnik SL, Classen DC, Clemmer TP, Weaver LK, Orme JF Jr, Lloyd JF, et al. A computer-assisted management program for antibiotics and other antiinfective agents. N Engl J Med 1998;338(4):232-8.

23. Bates DW, Teich JM, Lee J, Seger D, Kuperman GJ, Ma'Luf N, et al. The Impact of Computerized Physician Order Entry on Medication Error Prevention. J Am Med Inform Assoc 1999;6(4):313-21.

24. Bates DW, Leape LL, Cullen DJ, Laird N, Petersen LA, Teich JM, Burdick E, et al. Effect of computerized physician order entry and a team intervention on prevention of serious medication errors. Jama 1998;280(15):1311-6.

25. Borst F, Appel R, Baud R, Ligier Y, Scherrer JR. Happy birthday DIOGENE: a hospital information system born 20 years ago. Int J Med Inform 1999;54(3):157-67.

26. Scherrer JR. The integrated real-time hospital information system: DIOGENE. World Hosp 1983;19(4):8-11.

27. Scherrer JR, Baud RH, Hochstrasser D, Ratib O. An integrated hospital information system in Geneva. MD Comput 1990;7(2):81-9.

28. Peterson HE. From punched cards to computerized patient records: a personal journey. Methods Inf Med 2006;45 Suppl 1:180-6.

29. Sjoborg B, Backstrom T, Arvidsson LB, AndersenKarlsson E, Blomberg LB, Eiermann B, et al. Design and implementation of a point-of-care computerized system for drug therapy in Stockholm metropolitan health region-Bridging the gap between knowledge and practice. Int J Med Inform $2007 \mathrm{Jul} ; 76(7): 497-506$.

30. Bakker AR, Leguit FA. Evolution of an integrated 
HIS in The Netherlands. Int J Med Inform 1999;54(3):209-24.

31. Kalmeijer MD, Holtzer W, van Dongen R, Guchelaar HJ. Implementation of a computerized physician medication order entry system at the Academic Medical Centre in Amsterdam. Pharm World Sci 2003;25(3):88-93.

32. Boon WM, Westerhof HP, Duisterhout JS, Cromme PV.The role of AIDA in a primary care information system. Comput Methods Programs Biomed 1987;25(3):287-96.

33. van der Lei J, Duisterhout JS, Westerhof HP, van der Does E, Cromme PV, Boon WM, et al. The introduction of computer-based patient records in The Netherlands. Ann Intern Med 1993;119 (10):1036-41.

34. Poley MJ, Edelenbos KI, Mosseveld M, van Wijk MA, de Bakker DH, van der Lei J, et al. Cost consequences of implementing an electronic decision support system for ordering laboratory tests in primary care: evidence from a controlled prospective study in the Netherlands. Clin Chem 2007:53(2):213-9.

35. van Wijk MA, van der Lei J, Mosseveld M, Bohnen AM, van Bemmel JH. Assessment of decision support for blood test ordering in primary care. a randomized trial. Ann Intern Med 2001;134(4):274-81.

36. Kuilboer MM, van Wijk MA, Mosseveld M, van der Does E, de Jongste JC, Overbeek SE, et al. Computed critiquing integrated into daily clinical practice affects physicians' behavior - a randomized clinical trial with AsthmaCritic. Methods Inf Med 2006;45(4):447-54.

37. Ogura H, Yamamoto K, Furutani H, Kitazoe Y, Hirakawa M, Sagara E. On-line prescription order and prescription support in an integrated hospital information system. Med Inform (Lond) 1985; 10(4):287-99.

38. Ogura H, Sagara E, Yamamoto K, Furutani H, Kitazoe Y, Takeda Y. Analysis of the online order entry process in an integrated hospital information system. Comput Biol Med 1985;15(6):381-93.

39. Ogura H, Sagara E, Iwata M, Nishioka Y, Furutani $\mathrm{H}$, Yamamoto K, Kitazoe Y. Online support functions of prescription order system and prescription audit in an integrated hospital information system. Med Inform (Lond) 1988;13(3):161-9.

40. Hasman A, Safran C, Takeda H. Quality of health care: informatics foundations. Methods Inf Med 2003;42(5):509-18.

41. Haruki Y, Ogushi Y, Okada Y, Kimura M, Kumamoto I, Sekita Y. Status and perspective of hospital information systems in Japan. Methods Inf Med 1999;38(3):200-6.

42. Matsumura Y, Takeda H, Inoue M. Implementation of the totally integrated hospital information system (Humane) in Osaka University Hospital. Medinfo 1995;8 Pt 1:590-3.

43. Park RW, Shin SS, Choi YI, Ahn JO, Hwang SC. Computerized physician order entry and electronic medical record systems in Korean teaching and general hospitals: results of a 2004 survey. J Am Med Inform Assoc 2005;12(6):642-7.

44. Hwang JI, Park HA, Bakken S. Impact of a physician's order entry (POE) system on physicians' ordering patterns and patient length of stay. Int J Med Inform 2002;65(3):213-23.

45. Park WS, Kim JS, Chae YM, Yu SH, Kim CY,
Kim SA, et al. Does the physician order-entry system increase the revenue of a general hospital? Int $J$ Med Inform 2003;71(1):25-32.

46. Thompson W, Dodek PM, Norena M, Dodek J. Computerized physician order entry of diagnostic tests in an intensive care unit is associated with improved timeliness of service. Crit Care Med 2004;32(6):1306-9.

47. Kuperman GJ, Gibson RF. Computer physician order entry: benefits, costs, and issues. Ann Intern Med 2003;139(1):31-9.

48. Ozdas A,Speroff T, Waitman LR, Ozbolt J, Butler J, Miller RA. Integrating "best of care" protocols into clinicians' workflow via care provider order entry: impact on quality-of-care indicators for acute myocardial infarction. J Am Med Inform Assoc 2006;13(2):188-96.

49. Teich JM,Merchia PR, Schmiz JL, Kuperman GJ, Spurr CD, Bates DW. Effects of computerized physician order entry on prescribing practices. Arch Intern Med 2000;160(18):2741-7.

50. Kucher N, Koo S, Quiroz R, Cooper JM, Paterno MD, Soukonnikov B, et al. Electronic alerts to prevent venous thromboembolism among hospitalized patients. N Engl J Med 2005;352(10):969-77.

51. Shojania KG, Yokoe D, Platt R, Fiskio J, Ma'luf $\mathrm{N}$, Bates DW. Reducing vancomycin use utilizing a computer guideline: results of a randomized controlled trial. J Am Med Inform Assoc 1998; 5(6):554-62.

52. Jha AK, Kuperman GJ, Teich JM, Leape L, Shea B, Rittenberg E, et al. Identifying Adverse Drug Events: Development of a Computer-based Monitor and Comparison with Chart Review and Stimulated Voluntary Report. J Am Med Inform Assoc 1998;5(3):305-14.

53. Neilson EG, Johnson KB, Rosenbloom ST, Dupont WD, Talbert D, Giuse DA, et al. The impact of peer management on test-ordering behavior. Ann Intern Med 2004;141(3):196-204.

54. Tierney WM, Miller ME, McDonald CJ, The effect on test ordering of informing physicians of the charges for outpatient diagnostic tests. N Engl J Med 1990;322(21):1499-504.

55. Bates DW, Kuperman GJ, Jha A, Teich JM, Orav EJ, Ma'luf N, et al. Does the computerized display of charges affect inpatient ancillary test utilization? Arch Intern Med,1997;157(21):2501-8.

56. Bates DW, Kuperman GJ, Rittenberg E, Teich JM, Fiskio J, Ma'luf N, et al.,A randomized trial of a computer-based intervention to reduce utilization of redundant laboratory tests. Am J Med 1999;106(2):144-50.

57. Tierney WM, McDonald CJ, Martin DK, Rogers MP. Computerized display of past test results. Effect on outpatient testing. Ann Intern Med 1987;107(4):569-74

58. Tierney WM, McDonald CJ, Hui SL, Martin DK. Computer predictions of abnormal test results. Effects on outpatient testing. Jama 1988; 259(8):1194-8.

59. Sanders DL, MillerRA. The effects on clinician ordering patterns of a computerized decision support system for neuroradiology imaging studies. Proc AMIA Symp 2001. p. 583-7.

60. Harpole LH, Khorasani R, Fiskio J, Kuperman GJ, Bates DW. Automated Evidence-based Critiquing of Orders for Abdominal Radiographs: Impact on
Utilization and Appropriateness. J Am Med Inform Assoc 1997;4(6):511-21.

61. Chin HL, Wallace P. Embedding guidelines into direct physician order entry: simple methods, powerful results. Proc AMIA Symp 1999. p. 221-5.

62. Bates DW, Cullen DJ, Laird N, Petersen LA, Small $\mathrm{SD}$, Servi $\mathrm{D}$, et al. Incidence of adverse drug events and potential adverse drug events. Implications for prevention. ADE Prevention Study Group. Jama 1995;274(1):29-34.

63. Chertow GM, Lee J, Kuperman GJ, Burdick E, Horsky J, Seger DL, et al. Guided medication dosing for inpatients with renal insufficiency. Jama 2001;286(22):2839-44.

64. Bobb,A, Gleason K, Husch M, Feinglass J, Yarnold PR, Noskin GA. The epidemiology of prescribing errors: the potential impact of computerized prescriber order entry. Arch Intern Med 2004;164(7):785-92.

65. Evans RS, Pestotnik SL, Classen DC, Clemmer TP, Weaver LK, Orme JF Jr, et al. A ComputerAssisted Management Program for Antibiotics and Other Antiinfective Agents. N Engl J Med 1998;338(4): 232-8.

66. Classen DC, Pestotnik SL, Evans RS, Lloyd JF, Burke JP. Adverse drug events in hospitalized patients. Excess length of stay, extra costs, and attributable mortality. Jama 1997;277(4):301-6.

67. Tierney WM, Miller ME, Overhage JM, McDonald CJ. Physician inpatient order writing on microcomputer workstations. Effects on resource utilization. Jama 1993; 269(3):379-83.

68. Peterson JF, Kuperman GJ, Shek C, Patel M, Avorn J, Bates DW. Guided prescription of psychotropic medications for geriatric inpatients. Arch Intern Med 2005;165(7):802-7.

69. Potts AL, Barr FE, Gregory DF, Wright L, Patel NR. Computerized physician order entry and medication errors in a pediatric critical care unit. Pediatrics 2004;113(1 Pt 1):59-63.

70. Schiff GD, Klass D, Peterson J, Shah G, Bates DW. Linking laboratory and pharmacy: opportunities for reducing errors and improving care. Arch Intern Med 2003;163(8):893-900.

71. Payne TH, Hoey PJ, Nichol P, Lovis C. Preparation and use of preconstructed orders, order sets, and order menus in a computerized provider order entry system. J Am Med Inform Assoc 2003;10(4):322-9.

72. Bobb AM, Payne TH, Gross PA, Viewpoint: controversies surrounding use of order sets for clinical decision support in computerized provider order entry. J Am Med Inform Assoc 2007;14(1):41-7.

73. Gross PA, Bates DW. A pragmatic approach to implementing best practices for clinical decision support systems in computerized provider order entry systems. J Am Med Inform Assoc 2007;14(1):25-8.

74. Butler J, Speroff T, Arbogast PG, Newton M, Waitman LR, Stiles R, et al. Improved compliance with quality measures at hospital discharge with a computerized physician order entry system. Am Heart J 2006;151(3):643-53.

75. Ash JS, Stavri PZ, Kuperman GJ. A consensus statement on considerations for a successful CPOE implementation. J Am Med Inform Assoc 2003;10(3):229-34.

76. Bates DW, Kuperman GJ, Wang S, Gandhi T, Kittler 
A, Volk L, et al. Ten commandments for effective clinical decision support: making the practice of evidence-based medicine a reality. J Am Med Inform Assoc 2003;10(6):523-30.

77. Teich JM, Osheroff JA, Pifer EA, Sittig DF, Jenders RA; The CDS Expert Review Panel. Clinical decision support in electronic prescribing: recommendations and an action plan: report of the joint clinical decision support workgroup. J Am Med Inform Assoc 2005;12(4):365-76.

78. Miller RA, Gardner RM, Johnson KB, Hripcsak G. Clinical decision support and electronic prescribing systems: a time for responsible thought and action. J Am Med Inform Assoc 2005; 12(4):403-9.

79. McDonald CJ, Overhage JM, Mamlin BW, Dexter PD, Tierney WM. Physicians, information technology, and health care systems: a journey, not a destination. J Am Med Inform Assoc 2004; 11(2):121-4.

80. Aarts J, Doorewaard H, Berg M. Understanding implementation: the case of a computerized physician order entry system in a large Dutch university medical center. J Am Med Inform Assoc 2004;11(3):207-16.

81. Coiera, E. Four rules for the reinvention of health care. Bmj 2004;328(7449):1197-9.

82. Georgiou A, Westbrook JI, Computerised order entry systems and pathology services - a synthesis of the evidence. Clin Biochem Rev 2006;27(2):79-87.

83. Beuscart-Zephir MC, Pelayo S, Anceaux F, Meaux JJ, Degroisse M, Degoulet P. Impact of CPOE on doctor-nurse cooperation for the medication ordering and administration process. Int J Med Inform 2005;74(7-8):629-41.

84. Coiera, E. When conversation is better than computation. J Am Med Inform Assoc 2000; 7(3):277-86.

85. Stead WW, Baker W, Harris TR, Hodges TM, Sittig DF. A fast track to IAIMS: the Vanderbilt University strategy. Proc Annu Symp Comput Appl Med Care 1992. p. 527-31.

86. Koppel R, Metlay JP, Cohen A, Abaluck B, Localio AR, Kimmel SE, et al. Role of computerized physician order entry systems in facilitating medication errors. Jama 2005;293(10):1197-203.

87. Miller RA, Gardner RM. Recommendations for responsible monitoring and regulation of clinical software systems. American Medical Informatics Association, Computer-based Patient Record Institute, Medical Library Association, Association of Academic Health Science Libraries, American Health Information Management Association, American
Nurses Association. J Am Med Inform Assoc 1997;4(6):442-57.

88. Kuperman GJ, Bobb A, Payne TH, Avery AJ, Gandhi TK, Burns G, et al. Medication-related clinical decision support in computerized provider order entry systems: a review. J Am Med Inform Assoc 2007:14(1):29-40.

89. Classen DC, Avery AJ, Bates DW. Evaluation and certification of computerized provider order entry systems. J Am Med Inform Assoc 2007;14(1):48-55.

90. Nebeker JR, Hoffman JM, Weir CR, Bennett CL, Hurdle JF. High rates of adverse drug events in a highly computerized hospital. Arch Intern Med 2005;165(10):1111-6.

\section{Correspondence to:}

Asli Ozdas, PhD

Eskind Biomedical Library-LL

2209 Garland Avenue

Nashville, TN 37232-8340

USA

Tel: +16159367520

Fax: +16159365900

E-mail: asli.ozdas@vanderbilt.edu 